Ekaterina Vladimirovna Kazakova

Institut de philologie et de journalisme, Université nationale de recherche

N. Lobatchevski, Nijni Novgorod

Russie

kazakova.e.v@gmail.com

Natalia Aleksandrovna Voskressenskaia

Institut de philologie et de journalisme, Université nationale de recherche N. Lobatchevski, Nijni Novgorod

Russie

voskressen@gmail.com
UDK 821.133.1.09-32Tesson S. DOI: 10.4312/vestnik.12.69-74

\title{
REPRÉSENTATION ET INTERPRÉTATION DU CONCEPT DE POFIGISME DANS LE RÉCIT DE SYLVAIN TESSON « LE TRAIN »
}

Tout récemment, le lecteur français a découvert un nouveau mot introduit par Sylvain Tesson dans son recueil S'abandonner à vivre. Le mot pofigisme représente un concept important pour la culture russe. Employé occasionnellement, ce lexème ne s'est pas encore généralisé : l'analyse de son utilisation contextuelle sur Internet démontre que 90\% des cas d'utilisation font référence à Sylvain Tesson.

L'écrivain explique le sens de la notion nouvellement introduite et expose le contenu culturel et philosophique du pofigisme, notamment dans le récit « Le train » (Tesson, 2014). Puisque le lexème représentant le concept culturel est une transcription du mot russe et ne porte pas de charge sémantique pour le lecteur français, il est important de comprendre le champ associatif du concept.

Sylvain Tesson trouve les signes d'une certaine indifférence à la vie en fonction des cultures. Il convient pourtant de remarquer que trois récits racontent les vies des Russes : "Les Russes sont tous atteints à des degrés divers par cette torpeur métaphysique » (Tesson : 220).

L'auteur construit le champ lexical du phénomène dès le début du récit : " J'ai été initié à la vérité du "pofigisme » " (Ibid., p. 219). Le narrateur propose sa vision personnelle du concept en exposant les aspects positifs et négatifs de ce dernier, en mettant en relief le caractère complexe, ambigu de la composante importante du caractère national russe. Une vision de la vie particulière, et ignorée jusque-là de l'écrivain, car différente de la sienne, inhérente à sa culture, intègre des éléments sémantiquement opposés : résignation et joie, joie et désespérance, action et inertie. L'inertie et la passivité, qualités essentielles à un 
pofigiste, constituent une vertu aux yeux de l'écrivain : ayant fait face aux réalités de la vie, ces gens ne résistent plus, «ils s'abandonnent à vivre » (Ibid., p. 220).

La définition développée du pofigisme ouvre l'intrigue du récit : "Pofigisme n'a pas de traduction en français. Ce mot russe désigne une attitude face à l'absurdité du monde et à l'imprévisibilité des évènements. Le pofigisme est une résignation joyeuse, désespérée face à ce qui advient. Les adeptes du pofigisme, écrasés par l'inéluctabilité des choses, ne comprennent pas qu'on s'agite dans l'existence. Pour eux, lutter à la manière des moucherons piégés dans une toile d'argiope est une erreur, pire, le signe de la vulgarité. Ils accueillent les oscillations du destin sans chercher à en entraver l'élan. Ils s'abandonnent à vivre » (loc.cit.). La métaphore choisie pour décrire les Russes ressemble à une prise de position bien réfléchie quant à ceux qu'elle caractérise : l'impuissance face au destin est assumée, la résignation est plus appréciable à leurs yeux que l'agitation inutile, les pofigistes s'approchent alors passivement du dénouement de leurs vies.

Les moucherons slaves s'opposent aux hamsters de «l'Europe de Schengen » toujours " affairés [...] dans leur cage de plastique tournant sur elle-même » (loc.cit.). Ces comparaisons métaphoriques, faisant référence à des catégories de nature différentes, se révèlent symboliques en tant qu'illustrations, et cruciales en tant que vision du monde et acception de soi au sein de sa propre culture, c'est justement ce qui oppose les représentants des nationalités évoquées, de cultures différentes. Les uns optent pour une action, les autres, au contraire, l'inaction. Les uns prennent la vie comme une variation de choix à faire, les autres la voient plutôt comme une destinée inévitable, dont l'itinéraire est impossible à changer. Sans mentionner ce qu'en pensent les Slaves, S. Tesson fait observer que les Européens " méprisent ce penchant à l'inertie [...] lui donnent le nom de fatalisme, font la moue devant la passivité slave» (loc.cit.). Vu que la fin de la vie sera la même pour tous, l'écrivain conclut que les « hamsters" ont tout simplement oublié les avantages de prendre la vie comme elle vient. Il montre ainsi les aspects positifs de la vie des « moucherons ».

Or, la comparaison n'est pas fortuite, elle dévoile la différence en perceptions du monde et son appropriation, dans la perspective onomasiologique, par des consciences appartenant à des nationalités différentes. C'est exactement par la voie de la perception (dans sa vision du mode de vie et dans son expression linguistique) que le caractère national se forge. Dans l'exemple métaphorique analysé, le concept national français de « savoir-vivre » est implicitement illustré par opposition à celui du pofigisme. Le moucheron désignant l'humain possède une connotation négative, dessinant un sujet invisible, désagréable à affronter, incommodant. Dans la conscience du sujet parlant, le hamster est un animal plus connu et assimilé à la vie humaine. Nous voyons ses activités, considérées comme inutiles et pourtant vues comme une forme de vie et d'organisation, une forme active et plutôt appréciable. Malgré les remarques de l'auteur sur l'aspect positif des pofigistes dans leur façon d'appréhender la vie, une telle comparaison met en lumière les attitudes et les pratiques culturelles des Français (voire des Européens) : les verbes d'action et de jugement (mépriser, faire la moue, partir vaquer) et les caractéristiques de l'action 
(affairé, les manches retroussées, sourcils froncés) pour décrire les Européens, sont opposés aux verbes d'inaction (accueillir, ne pas chercher, s'abandonner) et au verbe d'état (être écrasé) pour dire les Slaves.

Le champ lexical du pofigisme, tel que l'emploie l'auteur, est constitué de lexèmes dont la sémantique laisse sous-entendre que le narrateur n'accepterait pas cette vision du monde, même si elle s'inscrit dans une certaine vérité. Le verbe abandonner, placé dans le titre du livre et faisant partie de la définition du pofigisme, signifie «ne plus avoir la volonté de faire ou avoir quelque chose, confier quelque chose à l'autre ou au pouvoir de quelque chose ; laisser quelqu'un dont on doit s'occuper ; quitter définitivement (un lieu) ; renoncer à (une action difficile, pénible); cesser d'employer, ne plus considérer comme utile, bon ». La sémantique du verbe réfléchi s'abandonner est bien variée dans le sens des connotations et parle d'une action, d'un choix, par manque de forces physiques ou psychologiques « se laisser aller à (un sentiment, un état); se détendre, se laisser aller physiquement »; et en même temps, par assurance « se livrer en toute confiance » (Le Petit Robert, 2003). Le Dictionnaire analogique (2011) nous donne les collocations suivantes : s'abandonner au désespoir, s'abandonner à la joie, ce qui prouve la variabilité des connotations. La capacité du verbe s'abandonner à se combiner avec les mots de connotations différentes permet d'éviter de prendre l'expression s'abandonner à vivre dans le sens négatif uniquement, d'autant plus que le mot vivre est neutre. À la lumière des lexèmes analysés qui font partie du champ lexical du pofigisme, on sous-entend une vision favorable d'appréhender et vivre la vie. C'est justement ce qu'ont fait les participants à un forum en ligne ${ }^{1}$ lors de la discussion de ce phénomène évoqué par Sylvain Tesson.

Néanmoins, pour la conscience linguistique française, l'interprétation positive de l'expression s'abandonner à vivre s'avère peu probable puisque l'unité lexicale centrale de sa définition - résignation - renferme une connotation négative. Sa définition dans le dictionnaire témoigne d'un choix sans contrainte, pourtant pas toujours appréciable « abandon; le fait d'accepter sans protester (la volonté d'une autorité supérieure), tendance à se soumettre, à subir sans réagir » (Le Petit Robert, 2003). L'idée de la soumission et le caractère contradictoire de ce mode de vie sont également renforcés par la fusion des lexèmes désespéré et joyeux dont les connotations ne semblent pas pouvoir créer un ensemble logique. Ces caractéristiques se contredisent non seulement au niveau des sentiments qu'elles représentent mais aussi au niveau de l'activité sous-entendue par les actes qu'elles accompagnent : le mot désespéré ajoute de la passivité à l'action ou à un sentiment éprouvé (à l'exception de certaines collocations marquées dans le dictionnaire, comme avec les verbes crier, exprimer, hurler, laisser éclater, selon le Dictionnaire analogique, 2001). Le mot joyeux, au contraire, s'emploie avec des noms d'actions et d'états actifs. Ainsi, une telle opposition met en lumière le caractère contradictoire de l'esprit russe, bien perçu par l'écrivain.

1 http://lesbilletsdhumeurdeninon.eklablog.com/soyons-pofigistes-a106880084 
L'importance et le caractère global du phénomène dans la culture russe et sa propagation dans la société sont mis en évidence par le lexique et l'intrigue du récit. Sylvain Tesson écrit : "J'ai été initié à la vérité du " pofigisme » " (Ibid., p. 219). Ici, le lexème polysémantique vérité comprend une signification de la « connaissance de la plus grande valeur ; conforme au réel, connue ou à connaître ; idée ou proposition vraie qui l'importe ; un principe, un dogme (par exemple une vérité d'évangile) ». Le verbe d'action initier possède une signification spécifique à « [l'] acquisition, permission d'accéder à la connaissance ou à la participation de certains cultes ou certains rites secrets, à la pratique d'une religion ; à la connaissance d'un savoir peu répandu » (Le Petit Robert, 2003); ce verbe s'utilise donc souvent pour les groupes thématiques « religion, société secrète, groupe fermé ».

Le narrateur français se trouve dans un décor inhabituel et peu agréable : il est dans un train reliant Vladivostok et Khabarovsk, dans la zone transsibérienne des chemins de fer russes. L'endroit où se passe l'action donne son titre au récit, ce qui crée des associations avec l'endroit vide, l'endroit qui vit d'après ses propres lois et qui ne suppose pas de choix «Dans un train, pas de choix. Soit on remonte vers l'amont, soit on va vers l'aval» (Ibid., p. 221). Avant de prendre le train, le narrateur boit de la bière Baltica (russe) « $f$ dèle à la tradition russe qui recommande de se saouler avant un long voyage » (Ibid., p. 220). La structure du récit suit les étapes de l'initiation rituelle : l'histoire s'ouvre avec la description du lieu et de l'atmosphère ambiante, toutes typiques pour un rituel, puis se poursuit avec l'explicitation des étapes de l'initiation et des signes exprimant les particularités culturelles, et se résume enfin par une phrase contenant l'impératif du verbe et le mot désignant le nom du concept culturel en question, annoncé au début. Dans l'espace fermé, tous, que l'on imagine bien nombreux comme c'est souvent le cas, sont censés être initiés à la vérité du pofigisme. Pourtant, Sylvain Tesson n'introduit dans l'histoire que les personnages concernés, il se concentre sur les agents de l'histoire liés au rituel. Une seule fois, les « cris des témoins » sont mentionnés lors de la narration (Ibid., p. 222). Le point culminant a lieu à minuit : "la nuit masquait l'infinie tristesse de l'Extrême-Orient russe. Des Russes vivaient dans ce néant sous les cheminées. Je regardai ma montre. Minuit » (Ibid., p. 220-221). Ayant fait face à « un Ouzbek de cent dix kilos » (loc.cit.) qui lui coupait le passage, le narrateur refuse de le laisser passer en premier comme l'insistait celui-ci, se mêle à la bagarre dont il ressort blessé. De retour dans son compartiment, le Français est soigné par sa voisine Olga qui, «d'une voix ferme », lui conseille de ne pas y faire trop attention : "On s'en fout de ta plaie. Soit pofigiste, mec » (Ibid., p. 224).

Cette réplique clôture le récit, elle est précédée d'une remarque de l'auteur «En face de filles pareilles, il n'est pas étonnant que les nazis aient échoué à Stalingrad. » (loc.cit.) et met en valeur un aspect positif du pofigisme aux yeux des Français.

En résumé, il importe de mentionner le caractère controversé du phénomène culturel en question. Il se crée avec des procédés différents, linguistiques et de composition, et la création des images des personnages, les deux derniers contribuant à la connotation favorable du mode de vie à la russe (slave). Les lexèmes constituant son noyau sémantique, 
expriment pourtant le contraire. Ceci est expliqué par l'emploi du lexème résignation et sa connotation uniquement négative, ses interprétations dans la littérature classique ce qui influence sans doute la formation de la vision du monde par la nation. Ou comme le suggérait Honoré de Balzac : «La résignation, mon ange, est un suicide quotidien ». Sylvain Tesson, vu l'analyse de son interprétation artistique du phénomène, serait-il plutôt favorable vis-à-vis de l'appréhension quotidienne de la réalité dans sa version slave, ce qui est exprimé implicitement dans le récit « Le Train ».

\section{BIBLIOGRAPHIE}

TESSON, Sylvain (2014) S'abandonner à vivre. Paris : Gallimard.

Le Petit Robert. Dictionnaire de la langue française (2003) Paris : Le Robert. Dictionnaire analogique (2001) Paris : Larousse.

\section{POVZETEK}

\section{PRIKAZ IN INTERPRETACIJA KONCEPTA POFIGISME V PRIPOVEDI VLAK AVTOR-} JA SYLVAINA TESSONA

V prispevku analiziramo leksikalna izrazna sredstva, stilistične postopke in strategije za strukturiranje besedila, ki so uporabljeni pri predstavitvi ruskega (slovanskega) kulturnega koncepta, imenovanega pofigisme. Ta posebni koncept, ki ga lahko opišemo kot fatalizem v življenju in v njegovem dojemanju, je predstavil in ga v primerjavi s francosko umetnostjo življenja, imenovano savoir-vivre, analiziral francoski pisatelj Sylvain Tesson. Pomensko nasprotni si elementi, ki se pojavljajo v njegovi pripovedi Vlak, omogočajo metaforično primerjavo dveh različnih kultur. Leksemi, ki slikajo nasprotja, s svojim pomenom poudarjajo razlike v pogledu na svet in v posameznikovem dojemanju samega sebe v lastnem kulturnem okolju: aktivnost se sooči z inertnostjo. Avtor se kljub temu ne odloči za enega izmed obeh nazorov, kar dokazuje njegova izbira leksemov in nenavadnih kolokacij. Leksikalno polje koncepta pofigisme v Tessonovi literarni različici tvorijo leksemi, katerih pomen nakazuje, da avtor tega nazora ne podpira, vseeno pa ga predstavlja kot nekakšno resnico. To potrjuje tudi pripovedna struktura dela, ki odslikava stopnje obredne iniciacije. Kljub relativno pozitivnemu literarnemu prikazu osebe, ki sledi življenjskemu nazoru pofigisme, je evropski pogled na svet z osrednjimi leksemi v Tessonovem literarnem delu posredno prikazan kot ustreznejši.

Ključne besede: koncept, pofigisme, umetnost življenja, priložnostnica, značaj naroda 


\section{ABSTRACT \\ REPRESENTATION AND INTERPRETATION OF THE CONCEPT OF POFIGISM IN SYLVAIN TESSON'S “THE TRAIN"}

The article presents an analysis of the lexical expressive means, stylistic and text structuring devices used to present the Russian (Slavic) cultural concept of pofigism, which expresses a certain fatalism in the way of taking and living life. This particular feature has been described and analysed in parallel with the idea of savoir-vivre by the French writer Sylvain Tesson. Semantically opposed elements are chosen to introduce metaphorical comparisons of two distinct cultures. The lexemes chosen to realise this opposition and their semantics highlight the difference in visions of the world and sense of oneself in one's culture, with action facing inertia. The author, however, does not seem to settle on one of the positions, although his choice of lexemes and the non-obvious collocations speak of it. The lexical field of pofigism, in Tesson's version, consists of those lexemes whose semantics imply that the narrator's native culture does not accept this view of the world, even if this view is presented as a definite truth. This idea is supported by the narrative structure which follows the stages of ritual initiation. Despite the relatively positive image of the pofigist, the lexemes constituting this concept express the opposite point of view.

Keywords: concept, pofigism, savoir-vivre, occasionalism, national character

\section{RÉSUMÉ}

L'article propose l'analyse des moyens lexicaux, stylistiques et structuraux servant à présenter le concept culturel russe (slave) qui exprime un certain fatalisme dans la manière d'appréhender et de vivre la vie. Cette particularité a été décrite et analysée, en parallèle avec le savoir-vivre, par l'écrivain français Sylvain Tesson. Des éléments sémantiquement opposés sont choisis pour introduire des comparaisons métaphoriques de deux cultures assez distinctes. Les lexèmes choisis pour rendre compte de cette opposition et leur sémantique mettent en valeur la différence des visions du monde et l'acception de soi dans sa propre culture : l'action fait face à l'inertie. L'auteur ne semble pourtant pas décidé à se positionner : le choix des lexèmes et les collocations non évidentes en sont le reflet. Le champ lexical du «pofigisme », tel que l'emploie l'auteur, est constitué des lexèmes dont la sémantique sous-entend que le narrateur n'accepte pas cette vision du monde, même si elle est envisagée comme une certaine vérité. Cette dernière idée est soutenue par la structure du récit qui suit les étapes de l'initiation rituelle. Malgré l'image relativement positive du «pofigiste », les lexèmes constituant son noyau démontrent le contraire.

Mots-clés : concept, pofigisme, savoir-vivre, occasionnalisme, caractère national 